\title{
Artificial intelligence (Al) and robotics in travel, hospitality and leisure
}

\author{
Chulmo Koo $^{1} \cdot$ Zheng Xiang $^{2}$ - Ulrike Gretzel ${ }^{3} \cdot$ Marianna Sigala $^{4}$
}

Published online: 3 September 2021

(C) Institute of Applied Informatics at University of Leipzig 2021

With the ongoing COVID-19 pandemic, it has become even clearer that tourism is highly dependent on technological solutions. The continuing crisis calls for institutional innovation to conceptualize resilient, agile, and flexible strategic initiatives and operations (Gretzel, 2021). Smart technologies, such as artificial intelligence (AI) and robotics, are creating an important driving force for travel, hospitality, and leisure (THL) during the pandemic and beyond, paving the way for new business models, new customer touchpoints, and new value (co-)creation opportunities. These technologies facilitate human experiences, support critical business processes, and enable important governance aspects.

From the customer perspective, AI and robotics can provide structured automated services and enhanced experiences. From a firm perspective, they support customer engagement, the delivery of rich service, secure data acquisition, and increased employee productivity and efficiency (Alt, 2021). From a governance perspective, AI and

This article is part of the Topical Collection on Artificial Intelligence (AI) and Robotics in Travel, Tourism and Leisure

Chulmo Koo

helmetgu@khu.ac.kr

Zheng Xiang

philxz@vt.edu

Ulrike Gretzel

gretzel@usc.edu

Marianna Sigala

Marianna.Sigala@unisa.edu.au

1 Smart Tourism Education Platform (STEP), College of Hotel and Tourism Management, Kyung Hee University, Seoul, South Korea

2 The Howard Feiertag Department of Hospitality and Tourism Management, Pamplin College of Business, Virginia Tech, Blacksburg, VA, USA

3 USC Center for Public Relations, Annenberg School of Communication \& Journalism, University of Southern California, Los Angeles, CA, USA

4 UniSA Business, University of South Australia, Adelaide, Australia robotics widen the action radius, allow for the adoption of new governance models, and propel efficiency to new levels. As such, they help realize smart tourism agendas with their important emphasis on sustainability, resilience, and enhanced wellbeing. Thus, there are good reasons to stress smart tourism and AI as an important topic for THL in the foreseeable future (Xiang, 2021). AI and robotics will have a tremendous impact on customers, businesses, and communities alike, and these impacts are expected to be especially profound in the THL context.

Another important aspect of AI and robotics in the THL domain is their invaluable contribution to the preservation and appreciation of human achievements and representation of our collective cultural heritage. As the pandemic prevented direct social contacts and traditional cultural experiences, the masses flocked online to satisfy their deep social and cultural human needs with virtual experiences. Consequently, online representations of and connections with physical and intangible heritage have risen in importance and are creating new cultural spheres (Hunter, 2021). They also represent important efforts to enable the localglobal nexus. In this sense, technology-based social reality is another facet of smart tourism that builds on $\mathrm{AI}$ and robotics capabilities and requires further exploration.

$\mathrm{AI}$ and robotics have become critical topics in our social discourse and essential enablers in our everyday life (e.g., Devlin, 2018; Tegmark, 2017). They warrant specific attention in the THL context, which not only represents an increasingly dominant and valued aspect of our lives but also a growing mix of industries with enormous economic and social impacts. Indeed, activities in the THL domain are increasingly reliant upon technologies that can understand, anticipate, and act upon human needs to improve the personal experience and wellbeing and heighten operational effectiveness (Gretzel, 2021). Intelligent services using AI enable predictions and accuracy of key tasks and allow individuals, organizations, and governance agencies to respond more flexibly to major situational changes. In a world that faces ever more complex and simultaneous crisis events, such opportunities matter, and they must expand beyond 
work and beyond local contexts. Here, the THL domain provides an important lens that can expand our thinking about $\mathrm{AI}$ and robotics.

Intelligent systems and tourism have a long history (Gretzel, 2011). In travel and tourism, solution-based or platformbased tools such as recommender systems and chatbots have been developed to provide personalized, location-based, context-aware information services and customer support services such as hotel recommendations, destination selection, travel planning alternative itinerary/route options, and customer service and complaint management (Ricci, 2002; Fesenmaier et al., 2006). These tools are becoming increasingly pervasive in commercial applications due to the diffusion of the smartphone and of social media (particularly in the travel sector) (Al Emadi et al., 2021). Equipped with AI-based technology including voice-activated tools such as Alexa and Google Home, intelligent systems have been applied widely in everyday and travel contexts to assist our everyday life and leisure activities. They increasingly penetrate hospitality and transportation spaces to facilitate experience (co-)creation and customer service delivery. A variety of robotic tools and applications (Jing et al., 2021) have been adopted by hospitality operators, museums, theme parks, and the transportation sector to provide novel experiences, enhance service quality, and improve business processes and productivity (Tung \& Au, 2018).

While these technologies vary a great deal in terms of the level of sophistication, intelligence, automation, and sociability, they have grown to permeate many aspects of THL. Importantly, smart tourism development efforts around the world enable AI and robotics to be connected to physical infrastructure and other intelligent objects (Gretzel et al., 2015), giving agency and, importantly, autonomy and market power to intelligent machines (Verhoef et al., 2017). As a result, $\mathrm{AI}$ and robotics are rapidly transforming the way businesses operate and engage with their customers, while they also present many opportunities and challenges in value creation, industry structure, and operations within the THL context (Ivanov et al., 2017; Murphy et al., 2017). This wide adoption calls for more research to understand how these technologies affect various aspects of the THL domain.

Research on AI and robotics in THL is not necessarily unique but is growing fast and provides perspectives that help wider understandings of smart technologies. However, existing literature does currently not fully provide the highquality insights needed to anticipate and manage the effects of AI and robotics. Primarily focused on individual customer experiences and engagement as well as organizational experiences and operations (neglecting critical operational, restructuring, and transformational issues), it also does not take advantage enough of interdisciplinary opportunities to push beyond existing research frontiers. Considering the multidisciplinary nature of the THL field and the need for more comprehensive research on emerging technologies, there is an urgency for research on $\mathrm{AI}$ and robotics in THL contexts that tackles the issue from multiple perspectives using a wide array of approaches. To contribute to the literature on AI and robotics in the THL field and to broaden its scope was the motivation for this special issue.

In response to our call for papers, we received a considerable number of contributions from various countries including Spain, Germany, Korea, Canada, France, Monaco, Italy, United Arab Emirates (UAE), Austria, Poland, and the United States. The number of submissions reflects the increasing attention paid to AI and robotics in the THL domain. After a rigorous peer-review process, eight fulllength papers were published in this special issue. These papers cover a wide range of topics from authors in different countries and regions and spanning different disciplinary backgrounds.

The first article, co-authored by Daniel Belanche, Luis V. Casaló, Carlos Flavián, is "Frontline robots in tourism and hospitality: service enhancement or cost reduction?" The paper explored how customer attributions regarding firms' motivations to implement service robots (cost reduction vs. service enhancement) are affecting customer intentions to use and recommend the innovation. The study examined service robot usage in a restaurant context and also measured how attributions may be shaped by customers' perceptions of the robot's human-likeness and their affinity with the robot.

The second article, co-authored by Erica Mingotto, Federica Montaguti, and Michele Tamma, is "Challenges in redesigning operations and jobs to embody $\mathrm{AI}$ and robotics in services. Findings from a case in the hospitality industry." This action research-based study explored AI in the context of "Pepper", a humanoid robot, providing information to customers at a reception desk in an Italian hotel. The study highlights the importance of the humanoid robot in supporting front desk staff, elaborates on the role of customers in enabling interactions, and discusses implications for the future of service jobs.

The third article, co-authored by Aikaterini Manthiou, Phil Klaus, Volker G. Kuppelwieser, and William Reeves, is "Man vs machine: examining the three themes of service robotics in tourism and hospitality." This conceptual paper explored service robots in the tourism and hospitality context through three basic themes: deployment, acceptance, and ethical considerations. Importantly, it identified various research needs that will help move this field of inquiry forward.

The fourth article, co-authored by Katharina Blöcher and Rainer Alt, is "AI and robotics in the European restaurant sector: assessing potentials for process innovation in a high-contact service industry." This paper analyzed the current status of AI and robotics in the restaurant context and proposed a systematic identification of process innovation potentials. It noted that the use of AI and robotics in 
restaurants is still immature but suggested that restaurants are inclined to leverage technologies for service excellence.

The fifth article, co-authored by Kichan Nam, Christopher S. Dutt, Prakash Chathoth, Abdelkader Daghfous, and M. Sajid Khan, is "The adoption of artificial intelligence and robotics in the hotel industry: prospects and challenges." It examined robot adoption in Dubai-based hotels using the TOE (Technology, Organization, Environment) framework and interviewing senior hotel asset managers. Among other things, this paper pointed out that the hotel managers reflected on customers wishing to use diverse AI technologies with more advanced features. Thus, advanced AI-based solutions integrating real-time and data-driven service, cocreation, consumer-centricity, and experience enhancement need to be developed through collaborative efforts between hotels and external AI professionals.

The sixth article, co-authored by Lin Li, Kyung Young Lee, Emmanuel Emokpae, and Sung-Byung Yang, is "What makes you continuously use chatbot services? Evidence from Chinese online travel agencies." It identified five quality dimensions of chatbot services and examined their effects on user confirmation and use continuance intention. The paper also explored technology anxiety and found it to be a significant moderating factor.

The seventh article, co-authored by Barbara Neuhofer, Bianca Magnus, and Krzysztof Celuch and entitled "The impact of artificial intelligence on event experiences: a scenario technique approach," adopted service-dominant logic as a theoretical lens and the scenario approach as a methodological tool. It explored the impact of AI in the context of the 2018 Convening Leaders event of the Conference Management Association. Assisted by AI, the event obtained participants' information and matched them according to their interests and networking needs. The research identified $\mathrm{AI}$ as an important operant resource for events that enables value (co-)creation opportunities across the entire event ecosystem.

The final article, co-authored by Dobin Yim, Timothy Malefyt, and Jiban Khuntia, is "Is a picture worth a thousand views? Measuring the effects of travel photos on user engagement using deep learning algorithms." It developed a framework for processing and interpreting various photographic elements using deep learning algorithms and a structured crowdsourced categorization process. This paper tested the effect of subjective interpretation of photos on user engagement in an online travel review site setting based on narrative framing concepts.

We would like to thank all the authors for their contributions. We wish to express our gratitude especially to Professor Rainer Alt and Dr. Hans-Dieter Zimmermann, the Co-Editors-in-Chief of Electronic Markets, for supporting the creation of this special topic and for providing thoughtful and pertinent advice during all stages of the project. In addition, we would like to give our thanks particularly to the group of international reviewers. The reviewers' time and effort invested in the manuscripts helped improve the quality of all the papers published in this special issue.

The papers in this special issue address a wide range of topics related to AI and robotics in the THL domain. Consequently, we hope that our special issue will be a stepping stone for theoretical and practical contributions in this dynamic and ever more important context. Overall, the research presented in this special issue provides constructive discussions regarding the value of new AI technologies from consumer and business perspectives. Collectively, the papers chart important ways forward in terms of AIrelated research, AI integration and management, and AI development.

Acknowledgements This work was supported by the Ministry of Education of the Republic of Korea and the National Research Foundation of Korea (NRF-2019S1A3A2098438).

\section{References}

Al Emadi, N., Thirumuruganathan, S., Robillos, D. R., \& Jansen, B. J. (2021). Will you buy it now?: Predicting passengers that purchase premium promotions using the PAX model. Journal of Smart Tourism, 1(1), 53-64. https://doi.org/10.52255/smarttouri sm.2021.1.1.7

Alt, R. (2021). Digital transformation in the restaurant industry: Current developments and implications. Journal of Smart Tourism, 1(1), 69-74. https://doi.org/10.52255/smarttourism.2021.1.1.9

Devlin, K. (2018). Turned On: Science, Sex and Robots. Bloomsbury Publishing.

Fesenmaier, D. R., Wöber, K. W., \& Werthner, H. (Eds.). (2006). Destination recommendation systems: Behavioral foundations and applications. Cabi.

Gretzel, U. (2011). Intelligent systems in tourism: A social science perspective. Annals of Tourism Research, 38(3), 757-779. https:// doi.org/10.1016/j.annals.2011.04.014

Gretzel, U. (2021). Conceptualizing the smart tourism mindset: Fostering. Utopian thinking in smart tourism development, 1(1), 3-8. https://doi.org/10.52255/smarttourism.2021.1.1.2

Gretzel, U., Sigala, M., Xiang, Z., \& Koo, C. (2015). Smart tourism: Foundations and developments. Electronic Markets, 25(3), 179188. https://doi.org/10.1007/s12525-015-0196-8

Hunter, W. C. (2021). Cultural representations and experience in tourism: Two forms of mimesis. Journal of Smart Tourism, 1(1), 65-67. https://doi.org/10.52255/smarttourism.2021.1.1.8

Ivanov, S. H., Webster, C., \& Berezina, K. (2017). Adoption of robots and service automation by tourism and hospitality companies. Revista Turismo \& Desenvolvimento, 27(28), 1501-1517.

Jing, X., Tan, F., \& Zhang, M. (2021). Digital application of intangible cultural heritage from the perspective of cultural ecology. Journal of Smart Tourism, 1(1), 41-52. https://doi.org/10.52255/ smarttourism.2021.1.1.6

Murphy, J., Hofacker, C., \& Gretzel, U. (2017). Dawning of the age of robots in hospitality and tourism: Challenges for teaching and research. European Journal of Tourism Research, 15, 104-111.

Ricci, F. (2002). Travel recommender systems. IEEE Intelligent Systems, 17(6), 55-57. 
Tegmark, M. (2017). Life 3.0: Being human in the age of artificial intelligence. Knopf.

Tung, V. W. S., \& Au, N. (2018). Exploring customer experiences with robotics in hospitality. International Journal of Contemporary Hospitality Management, 30(7), 2680-2697. https://doi.org/10. 1108/IJCHM-06-2017-0322

Verhoef, P. C., Stephen, A. T., Kannan, P. K., Luo, X., Abhishek, V., Andrews, M., Bart, Y., Datta, H., Fong, N., Hoffman, D. L., Mantian Hu, M., Novak, T., Rand, W., \& Zhang, Y. (2017). Consumer connectivity in a complex, technology-enabled, and mobile-oriented world with smart products. Journal of Interactive Marketing, 40, 1-8. https://doi.org/10.1016/j.intmar.2017.06.001
Xiang, Z. (2021). Journal of smart tourism: A new platform to support and define an emerging field. Journal of Smart Tourism, 1(1), 1-2. https://doi.org/10.52255/smarttourism.2021.1.1.1

Publisher's note Springer Nature remains neutral with regard to jurisdictional claims in published maps and institutional affiliations. 